УДК 78.03+78.083.23

DOI https://doi.org/10.31723/2524-0447-2020-30-2-36

\author{
Чэжан Цзюньсун \\ ORCID: 0000-0001-8824-1674
}

аспирант кафедры теории музыки и композиции

Одесской национальной музыкальной академии

имени А. В. Неждановой

312024707@qq.com

\title{
ПЕРВАЯ ФОРТЕПИАННАЯ СОНАТА В ТВОРЧЕСТВЕ ФРАНЦА ШУБЕРТА КАК ИМПУЛЬС ДЛЯ РАЗВИТИЯ ЖАНРА
}

Цель работы. Исследование направлено на рассмотрение особенностей жманра сонаты и его внутренних свойств на примере первого образиа в творчестве Ф. Шуберта, представляющего собой начало активных поисков композитора в ииклическом наполнении произведения. Производится иелостный анализ произведения и всех составляющих его частей с точки зрения как циклической общности, так и их внутренней самостоятельности. Рассмотрены характерные особенности жанра, формообразования, а также специфика фактуры, основные структурные принципы тематизма и гармонии, позволяющие определить особое промежуточное положение искусства композитора на стыке классииизма и романтизма. Методология исследования основана на применении системно-структурного, исторического и аналитического методов, позволивших выявить, наряду с традиционными, и нестандартные приемы в построении сонатного жанра. Научная новизна. Впервые на основе подробного исследования Первой фортепианной сонаты Ф. Шуберта доказывается, что данное произведение демонстрирует новый подход к трактовке сонатного иикла - разомкнутого, открытого, как бы незавершенного, отражающего поиски раннего романтика и отображающие эстетику романтизма. Происходит разрушение традииии чередования жканровых моделей: быстро - медленно, медленно - быстро между частями сонаты. Выводы. Трехчастное построение Первой сонаты Ф. Шуберта создает ощущение драматургической неоконченности, тональной разомкнутости. Первая часть создана в сонатной форме. Здесь наряду с романтическими устремлениями композитора проявляются и ярко выраженные классические тенденции. Вторая часть написана в сложной трех-пятичастной форме с явными признаками рондо. Возникает впечатление, что произведение лишено финала, так как завершается менуэтом в доминантовой тональности. 
Наблюдается необычное сочетание частей в цикле: первая часть - сонатная форма, затем анданте и менуэт. Темповый план сонаты как бы восполняет состояние «отсутствия финала». Это свидетельствует не о классических тенденциях построения иикла с контрастным чередованием частей (как обычно считают музыковеды), а скорее о ииклических нарушениях и поисках. Так он воспринимал несовершенную действительность, неизвестность будущего, его непредсказуемость.

Ключевые слова: Шуберт, сонатный цикл, сонатная форма, трехчастность.

Zhang Junsong, Graduate Student at the Department of Music Theory and Composition of the Odessa National A. V. Nezhdanova Academy of Music

The first piano sonata in the works of Franz Schubert as an impetus for the development of the genre

Research objective. The study is aimed at consideration of the features of the sonata genre and its internal properties on the example of the first sample in the works of $F$. Schubert, representing the beginning of the composer's active search in the cyclical content of the work. A holistic analysis of the work and all its constituent parts is carried out, both from the point of view of cyclical commonness and their internal independence. The characteristic features of the genre, shaping, as well as the specifics of texture, main structural principles of thematism and harmony, which make it possible to determine the special intermediate position of the composer's art across classicism and romanticism, are considered. The methodology is based on the use of system and structural, historical and analytical methods, which made it possible to identify both traditional and non-standard techniques in the construction of the sonata genre. The scientific novelty. For the first time, on the basis of a detailed study of F. Schubert's first piano sonata, it is proved that this work demonstrates a new approach to the interpretation of the sonata cycle - interrupted, open, as if unfinished, reflecting the searches of the early romantic and reflecting the aesthetics of romanticism. There is a destruction of tradition alternation of genres between parts of sonata: fast - slow, slow - fast. Conclusions. The three-part construction of the first sonata by $F$. Schubert creates a feeling of dramatic incompleteness, tonal openness. The first part is created in the sonata form. Here, along with the composer's romantic aspirations, clearly defined classical tendencies are also manifested. The second part is written in a complex three-five-part form with clear signs of rondo. There is an impression that the work has no finale, since it ends with a minuet in a dominant key. An unusual combination of parts in the cycle takes place: the first part is the sonata form, then the andante and the minuet. The tempo plan of the sonata, as if makes up for the state of "no ending" and is typical for many cycles: quick - slow - quick. This testifies not so much to the classical tendencies of constructing a cycle with a contrasting alternation of parts (as musicologists usually believe), but rather to the cyclical search for the composer. As such he perceived imperfect reality, uncertainty of the future, its unpredictability.

Key words: Schubert, sonata cycle, sonata form, three-part form. 
Чжан Цзюньсун, аспірант кафедри теорії музики та композиції Одеської національної музичної академії імені А. В. Нежданової

Периа фортепіанна соната у творчості Франца Шуберта як імпульс для розвитку жанру

Мета роботи. Дослідження спрямовано на розгляд особливостей жанру сонати і його внутрішніх властивостей на прикладі першого зразка у творчості Ф. Шуберта, що являе собою початок активних пошуків композитора в ииклічному наповненні твору. Проводиться цілісний аналіз твору і всіх його складових частин із погляду як ииклічної спільності, так і їхньої внутрішньої самостійності. Розглянуто характерні особливості жанру, формотворення, а також специфіку фактури, основні структурні принципи тематизму $і$ гармонії, що дозволяють визначити особливе проміжне положення мистецтва композитора на межі класииизму та романтизму. Методологія дослідження трунтується на застосуванні системно-структурного, історичного й аналітичного методів, що дозволили виявити, поряд із традиційними, і нестандартні прийоми в побудові сонатного жсанру. Наукова новизна. Уперше на основі детального дослідження Першої фортепіанної сонати Ф. Шуберта доводиться, що цей твір демонструє новий підхід до трактування сонатного ииклу - розімкнутого, відкритого, ніби незавершеного, що відображає пошуки раннього романтика й естетику романтизму. Відбувається руйнування традиції чергування жканрових принципів між частинами сонати: швидко - повільно, повільно - швидко. Висновки. Тричастинна побудова Першої сонати Ф. Шуберта створює відчуття драматургічної незавершеності, тональної розімкнутості. Перша частина створена в сонатній формі. Тут поряд із романтичними прагненнями композитора виявляються $і$ яскраво виражені класичні тенденції. Друга частина написана у складній трьох-п'ятичастинній формі з явними ознаками рондо. Виникає вражкення, що твір позбавлений фіналу, оскільки завершується менуетом в домінантовій тональності. Відбувається незвичайне поєднання частин у циклі: перша частина - сонатна форма, потім анданте і менует. Темповий план сонати ніби заповнюе стан «відсутності фіналу» $і$ є типовим для багатьох ииклів: швидко - повільно - швидко. Це свідчить не стільки про класичні тенденції побудови ииклу з контрастним чергуванням частин (як зазвичай уважають музикознавці), а радше про циклічні пошуки композитора. Так він сприймав недосконалу дійсність, невідомість майбутнього, його непередбачуваність.

Ключові слова: Шуберт, сонатний иикл, сонатна форма, тричастинність.

Актуальность темы исследования. Сонаты для фортепиано занимают особое, очень важное место в творческом наследии Ф. Шуберта. Самобытность творческой фигуры ком- 
позитора состоит в том, что он, подобно венским классикам, гораздо чаще своих современников обращается к этому жанру. Именно в сонатном жанре ощущается ка наибольшая связь Ф. Шуберта с классическими традициями, так и активные поиски романтических тенденций.

Специфика немецкой музыкальной культуры XIX в. находит отображение в уникальном стилевом разнообразии. Наряду с сохранением наиболее ценных традиций национальной культуры происходит активный поиск новых творческих тенденций. Именно относительно этого указанного свойства творчество Ф. Шуберта занимает особенное положение. Интерес к фортепианным произведениям композитора постоянно усиливается, они все чаще появляются в программах концертов, в учебном репертуаре учащихся музыкальных училищ и студентов консерваторий, академий. Современная молодежь все более чутко воспринимает несовершенство окружающего мира. А исполнение фортепианных произведений композитора, несомненно, способствует самореализации в непростой современной культурной ситуации.

Тем не менее в литературе о жизни и творчестве Франца Шуберта, в монографиях П. Вульфиуса [1], Г. Гольдшмидта [2], Б. Кремнева [3] основное место занимает песенное и симфоническое творчество композитора, а фортепианным сонатам уделяется недостаточно внимания. Особенно мало исследований посвящено сонатам раннего периода творчества Ф. Шуберта.

Цель исследования - выявить стилевое своеобразие цикла Первой фортепианной сонаты Ф. Шуберта E-dur.

Изложение основного материала. Ф. Шуберт писал сонаты с 1815 г. до самого последнего года жизни.

Соната E-dur, написанная в феврале 1815 г., - первое произведение данного жанра в творчестве Ф. Шуберта. Состоит из трех частей. Она как бы без финала, разомкнутая содержательно, циклически и тонально.

Первая часть сонаты - Allegro, ma non troppo - E-dur создана в сонатной форме. Обобщенную схему первой части сонаты можно изобразить следующим образом: 


\begin{tabular}{|l|l|l|l|l|}
\hline Экспозиция & Разработка & Реприза \\
\hline ГП..........(СП) & ПП.........(3П) & & ГП & ПП \\
\hline $\mathrm{A}+\mathrm{B} ; \mathrm{A} 1+\mathrm{B} 1$ & $\mathrm{C}+\mathrm{C} 1+\mathrm{D}+\mathrm{C} 2$ & $\mathrm{~B} 2+\mathrm{E}+\mathrm{F}$ & $\mathrm{A} 2+\mathrm{A} 3$ & $\begin{array}{l}\mathrm{C}_{2}+\mathrm{D} 1+\mathrm{C}_{3} \\
2+\mathrm{C} 3+\mathrm{B} 3\end{array}$ \\
\hline $8+14 ; 12+12$ & $\begin{array}{l}8+10+21+(5) \\
+12\end{array}$ & $24+9+7$ & $22+24$ & $18+26+14$ \\
\hline $22+24$ & $\begin{array}{l}18+21+5+12 \\
\mathrm{H}-\mathrm{h}-\mathrm{H}-\mathrm{G} \\
-\mathrm{C}-\mathrm{H}\end{array}$ & & & \\
\hline E-dur & & & \\
\hline
\end{tabular}

Начинается соната сразу (без вступления) сферой главной партии (46 тактов), которая изложена как бы в свободной сложной двухчастной форме (А - B + A1 - B1). Формируется основное настроение сонаты: торжественное, радостное, оптимистическое.

Но в построении и форме сферы главной партии не все так однозначно. Здесь и экспозиционность, и срединность, и репризность, и связуемость.

Схема строения сферы главной партии (44 такта):

Главная партия

A $\quad$ B

$8 \quad 14$

A a 1 B Пер. c-d - cl a

A1

12

a 2 a 3

$4 \quad 3+1$

$\mathrm{D}-\mathrm{K} \mathrm{E} \quad \mathrm{E} \quad \mathrm{Cis} \quad \mathrm{A}$

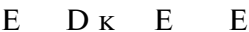

Сфера побочной партии звучит 58 тактов, она создана в трехчастной форме $(\mathrm{C}-\mathrm{C} 1-\mathrm{D}-\mathrm{C} 2)$ с постоянными совершенными кадансами.

Схема строения побочной партии экспозиции:

Собственно побочная партия

Выполняет функции заключительной партии

\begin{tabular}{|c|c|c|c|c|c|c|c|c|}
\hline \multicolumn{2}{|l|}{$\mathrm{C} \mathrm{Cl}$} & \multicolumn{4}{|l|}{$\mathrm{D}$} & \multicolumn{3}{|l|}{$\mathrm{C} 2$} \\
\hline $\mathrm{e}+\mathrm{e} 1$ & $\mathrm{e}+\mathrm{e} 1$ & $f+g$ & $F 1+f 2$ & g1 & Пер. & E2 & Доп. & Доп. \\
\hline $4+4$ & $4+6$ & $4+4$ & $\begin{array}{l}4+4 \\
55\end{array}$ & 5 & $2+3$ & 6 & $2+2$ & 2 \\
\hline H-dur & H-dur & $\mathrm{H}-\mathrm{h}$ & $\mathrm{H}-\mathrm{G}$ & $G-C$ & $\mathrm{C}-\mathrm{H}$ & H-dur & H-dur & $\mathrm{H}$ \\
\hline
\end{tabular}

Выполняет функцию связующей партии

B1

12

D 1 d 2 d 3

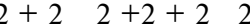

cis

$\mathrm{H}$ 
В основе побочной партии находится тематический элемент "b" из главной партии, где основой служили игривые форшлаги и нисходящие скачки на квинту. Тема побочной партии оказывается связанной интонационно и даже образно со сферой главной партии. Отметим также введение начального элемента dies irae в конце каждого периода (в 7-ых тактах), что вносит моменты «неизбежности» в лирическую сферу побочной.

$\Phi$. Шуберт сохраняет традиционное строение классической сонаты, создавая побочную партию в доминантовой тональности H-dur. Композитор использует характерную для побочной партии фактуру - альбертиевы басы, обозначает характер ее исполнения - dolce. Вся сфера побочной партии однотональная, ее характерной чертой стало использование тонико-доминантовой гармонии.

Средняя часть побочной партии (D) принципиально изменяет образность, динамику (f) и фактуру сонаты: появляются нисходящие ломаные арпеджио $(2+2)$, утверждается подчеркиванием sf аккордов D2 (во 2-ом и 4-ом тактах) к тонике H-dur.

Если часть D выполняет роль разработки в побочной партии, то часть С2 исполняет двойственную роль - реприз побочной и вместе с тем заключительной партии. Она несколько сокращена (14 тактов), вновь написана в форме периода с рядом дополнений. О заключительной функции свидетельствуют постоянный тонический органный пункт, появление восходящих интервалов, усложнение использованием хроматических ступеней, изменение фактуры тематического сопровождения. Строение репризы-заключения изобилует совершенными кадансами: $6+2+2+2$.

Обратим внимание на то, что в этой сонате Ф. Шуберта уже не повторяется экспозиция.

Вся разработка построена на развитии различных элементов побочной партии. Это основной элемент побочной, выросший из интонации " $b$ ” и “a” главной партии, - лежит в основе материала разработки. Также в разработке будут встречаться интонации из элементов $\mathrm{f}$ и g. Но самое важное, что здесь в фигурациях, сопровождающих тему побочной партии, активно развивается начальный элемент dies irae - вечное напоминание о бренности жизни.

Реприза повторяет все образы экспозиции в другом тональном соотношении. Происходит некоторая трансформа- 
ция текста - перенос на октаву выше: это касается середины Г. П. А в ее репризе (связующей партии) происходит утверждение основной тональности, что еще раз подтверждает ее связуюшую сущность, так же происходит и с завершением П. П., которая подтверждает свою заключительную функцию.

Отметим наиболее важные и яркие особенности первой части сонаты:

- наличие всего двух образных и тематических сфер главной и побочной партий;

- каждая из этих сфер совмещала в себе несколько функций: в главной сочетались особенности главной и связующей партий; в побочной - побочной и заключительной партий;

- обе формообразующие сферы написаны в форме свободной двух- (в главной сфере) либо трехчастности (в побочной сфере) с динамической репризой (повторностью) - вариантной, модулирующей, разомкнутой, тяготеющей к иной сфере психологии изложения - переходной, связующей, развивающе-заключительной;

- контрастная многоинтонационность музыкальной насыщенности каждой экспозиционной сферы: с одной стороны, чисто бетховенская контрастность внутреннего музыкального материала разного типа, вместе с тем сочетание иного, чуть ли не чужеродного, музыкального материала принципиально другой фактуры: в сфере главной партии объединено триольное восхождение по трезвучиям, гаммообразное движение, органный пункт; аккордовая хоральность, многократная его повторность; секвентное соотношение предложений, черты трехчастности; после начала точной репризы, ее продолжение в другой тональности с модуляцией в A-dur и др.)

Вторая часть сонаты - Andante - e-moll, 6/8. Обращает на себя внимание тональность - одноименный минор по сравнению с первой частью сонаты. Жанровая основа части своей формообразующей последовательностью и постоянной метричностью напоминает старинный французский аристократический танец на 6/8.

Andante написано в сложной трех-пятичастной форме с явными признаками рондо, каждая из частей создана в простой двух- или трехчастной репризной форме.

Первая из пяти частей (рефрен) содержит 16 тактов, два периода, построенные на одной ритмоформуле с использо- 
ванием пунктирного ритма, с вариантно повторенным мотивом “ $a$ ”.

Рефрен Andante создан в простой двухчастной форме с разработочной серединой и вариантной репризой, причем вторая часть повторена дважды, что свойственно танцевальным формам.

Вторая из пяти частей Andante - эпизод - вносит ощущение легкости, воздушности и даже нежности. Не меняя темпа и размера, композитор вносит ремарку легато. Светлый колорит тональности G-dur, упрощенно-причудливое мелодическое движение и постоянные шестнадцатые сопровождения и связок создают ощущение полетности. Как и в прежней части, здесь нет ощущения контрастов, используется тонико-доминантовые соотношения тональностей. Нарушается нормативность, так как предложения составляются по 6 т., а затем и квадратность - «полетная» середина шестнадцатых с элементом имитационности - 5 тактов. Вновь все построено на вариантности мотивного развития, в простой трехчастной форме с контрастной серединой.

Два такта перехода на новом призывно-вступительном мотиве приводят ко второму рефрену - вариационному повтору первой части.

Второй эпизод вносит ощутимый контраст: элегическая и задушевная тема e-moll (pp) неожиданно заменяется врывающейся энергичной и резкой, требовательной содержательностью, с постоянно меняющейся динамикой (ff $-\mathrm{p})$, меняется тональность на C-dur. Обратим внимание, что в рондальной форме классиков первый эпизод обычно пишется в доминантовой тональности, а второй - наиболее контрастный и в достаточно далекой тональности, так происходит и у Ф. Шуберта в этой части сонаты - Andante.

Как и предыдущий эпизод, этот написан в простой трехчастной форме с контрастной серединой и динамической сокращенной репризой. В эпизоде чередуются параллельные и субдоминантовые тональности. Интересно, что в первом периоде эпизода Ф. Шуберт создает пятитактовые предложения. Заканчивается эпизод пятью тактами перехода из C-dur в e-moll, что возвращает нас к рефрену.

Последний рефрен выполняет функцию репризы, она представляет собой очередную вариацию на рефрен. Вторая часть на этот раз впервые не повторяется. Завершая часть, 
Ф. Шуберт вводит 4 такта коды - утверждение основной тональности e-moll и напоминание о втором эпизоде. Кода прекрасно завершает драматургию второй части сонаты.

Третья, последняя часть сонаты E-dur - Менуэт - Allegro vivace, H-dur (тональность доминанты относительно основной E-dur), 3/4 - создана в традиционной сложной трехчастной репризной форме (da capo), в которой внутренние составные достаточно индивидуальны. Быстрый темп и светлая тональность H-dur придают основной теме (да и всей части) жизнерадостный, праздничный характер.

Крайние части Менуэта - Allegro vivace создают простую трехчастную форму (ARA1). Причем связана она с традициями классицизма: повторяется первая часть и затем вторая третья. Первая часть (А) длится 20 тактов, в которых происходит традиционный переход из основной тональности H-dur в доминантовую тональность Fis-dur.

Схема строения раздела А - экспозиции:

1-е предложение

2-е предложение

\begin{tabular}{|l|l|l|l|}
\hline a & a & a 1/в & доп. \\
\hline 4 & 4 & 10 & 2 \\
\hline H-dur & H-dur & H - Fis & Fis-dur \\
\hline ГП & CП & П & $3 \Pi$ \\
\hline
\end{tabular}

Разработка развивает первый и второй элементы части А, при этом обновляя мелодический мотив вариантом опевания. Полностью исчезает третий элемент раздела А; наблюдается также дробление фраз по 2, затем по 1 такту; неустойчивые гармонии DD и доминантовый органный пункт, а также тональные смены: fis-moll (минорная доминанта относительно основной тональности менуэта), D-dur (очень далекая тональность относительно ee), cis-moll (тональность II ступени), Fis-dur (доминантовая тональность). Отметим, что в разработке полностью теряется танцевальность, замененная постепенным нарастанием драматизма.

Реприза динамическая - A1 (20 тактов) возвращает танцевальность и утверждает тональность H-dur. Первое предложение - неизменное, во втором (повторном) происходит отклонение в gis-moll, затем утверждается H-dur. 
Возникает некоторое ощущение сонатных отношений в крайних разделах менуэта: экспозиция построена на тематическом контрасте (H-dur - Fis-dur), реприза повторяет те же элементы в основной тональности.

Схема репризы:

1-е предложение 2-е предложение

\begin{tabular}{|l|l|l|l|}
\hline a & a 2 & а 3/в & доп. \\
\hline 4 & 4 & 10 & 2 \\
\hline H-dur & gis-moll & H & HН \\
\hline ГП & CП & ПП & $3 \Pi$ \\
\hline
\end{tabular}

Таким образом, сложная трехчастная форма с разработкой в середине менуэта имеет некоторые черты сонатности.

Трио G-dur - sempre staccato (quasi portamento, см: $[4 ; 5]$ ) легкого, воздушного характера. Объединенные пульсирующим ритмом фразы и разделы, перетекают друг в друга. Как и менуэт, трио написано в простой трехчастной репризной форме В - R - В1. Создано трио в очень далекой тональности VI низкой ступени, что показательно для романтических тональных тенденций.

Первая часть (20 т.) создана в форме модулирующего ненормативного периода секвентного строения: а - а 1 - а $2-$ в + в 1 (в - как бы расширение: II 6/5 гарм. - Д - T, повторенное дважды на октаву ниже).

Средняя часть напоминает разработку: четвертная аккордика перемещается в правую руку, линия выдержанных звуков - в левую. Строение вновь секвентное: $\mathrm{H}-\mathrm{A}-\mathrm{G}$, затем D-dur и подготовка основной тональности G-dur. Трио все звучит затаенно, тихо (p, pp).

Схема строения трио:

\begin{tabular}{|c|c|c|c|c|c|c|c|c|c|c|c|c|c|c|c|}
\hline \multicolumn{5}{|l|}{ B } & \multicolumn{5}{|l|}{$\mathrm{R}$} & \multicolumn{6}{|c|}{ B1 } \\
\hline $\mathrm{a}$ & $a^{1}$ & a 2 & B & B 1 & C & c 1 & c 2 & e & e 1 & $\mathrm{a}$ & a 1 & a 2 & B 2 & в 3 & $->$ \\
\hline 4 & 4 & 4 & 4 & 2 & 4 & 4 & 4 & 4 & $4+4$ & 4 & 4 & 4 & 4 & 2 & 2 \\
\hline$G$ & G & D & D & D & $\mathrm{H}$ & $\mathrm{A}$ & G & & & $\mathrm{G}$ & $G$ & C & G & & \\
\hline
\end{tabular}

После трио, как обычно для менуэта, повторяется первая часть da саро. 
Заменяют ли менуэт и трио полноценный традиционный финал? Ни в коем случае. Возникает ощущение неоконченности драматургической, тональной, ощущение разомкнутости цикла.

Выводы. Первый образец сонатного жанра в творчестве Ф. Шуберта представляет собой начало активных поисков композитора в циклическом наполнении произведения. Трехчастное построение создает ощущение драматургической неоконченности, тональной разомкнутости.

Первая часть создана в сонатной форме. Здесь наряду с романтическими устремлениями Ф. Шуберта проявляются и ярко выраженные классические тенденции. Вторая часть написана в сложной трех-пятичастной форме с явными признаками рондо. Возникает впечатление, что произведение лишено финала, так как завершается менуэтом в доминантовой тональности. Наблюдается необычное сочетание частей в цикле: первая часть - сонатная форма, затем анданте и менуэт. Темповый план сонаты как бы восполняет состояние «отсутствия финала» и является типичным для многих циклов: быстро - медленно - быстро. Это свидетельствует не столько о классических тенденциях построения цикла с контрастным чередованием частей (как обычно считают музыковеды), а скорее о циклических поисках композитора. Так он воспринимал несовершенную действительность, неопределенность будущего, его непредсказуемость.

\section{СПИСОК ЛИТЕРАТУРЫ}

1. Вульфиус П. Франц Шуберт : Очерки жизни и творчества. Москва : Музыка, 1983. 447 с.

2. Гольдшмидт Г. Франц Шуберт. Жизненный путь. Перев. и прим. Ю. Хохлова. Москва : Музыка, 1968. 449 с.

3. Кремнев Б. Шуберт. Москва : Молодая гвардия, 1964. 301 с.

4. Мирошниченко С. Полисемия понятия quasi. Музичне мистецтво і культура. Науковий вісник Одеської державної музичної академії імені А.В. Нежданової. Одеса : Друкарський дім, 2010. Вип. 12. C. $49-58$.

5. Мирошниченко С. Полисемия понятия quasi. Вторая статья. Музичне мистецтво і культура. Науковий вісник Одеської державної музичної академії ім. А.В. Нежданової. Одеса : Друкарський дім, 2011. Вип. 13. С. 9-19. 


\section{REFERENCES}

1. Vulfius, P. (1983). Franz Schubert: Essays on life and work. Moscow: Muzyka [in Russian].

2. Goldshmidt, G. (1968). Franz Schubert. Way of life. Translation and notes by Yu.N. Khokhlov. Moscow: Muzyka [in Russian].

3. Kremnev, B. (1964). Schubert. Moscow: Molodaya gvardiya [in Russian].

4. Miroshnichenko, S.V. (2010). Polysemy of the concept quasi. Musical art and culture. Scientific Bulletin of the A.V. Nezhdanova Odessa State Musical Academy, 12, 49-58 [in Ukrainian].

5. Miroshnichenko, S.V. (2011). Polysemy of the concept quasi. Second article. Musical art and culture. Scientific Bulletin of the A.V. Nezhdanova Odessa State Musical Academy, 13, 9-19 [in Ukrainian]. 